\title{
Occupational Hazards in Oral Healthcare Professionals
}

${ }^{1}$ M Kshirsagar Minal, ${ }^{2}$ Jagdishchandra Vathar, ${ }^{3}$ Harshal Bafna, ${ }^{4}$ Kapil R Sonawane, ${ }^{5}$ Sandhya Naik, ${ }^{6}$ Suryakant Powar

\begin{abstract}
Introduction: Occupational hazards are disorders which are induced due to work-related conditions. Oral healthcare providers are continuously getting exposed to a number occupation-related disorders. This may cause various occupation-related disorders which then develop and increase with years. Unawareness or ignorance makes oral healthcare professionals more vulnerable to occupationrelated disorders. So health of oral healthcare professionals, especially effect of dental activities on it, is important in the present day, and as a matter of fact, not a well-documented subject also.
\end{abstract}

Aim: To summarize the important side of occupation-related disorders influencing oral healthcare professionals and to present its preventive measures.

Results: Previous literature suggests evidence of high vulnerability of oral healthcare professionals to certain work-related disorders.

Conclusion: It is therefore, important that all the oral healthcare professionals remain constantly informed regarding occupational hazards and implementation of preventive strategies to provide a safe working environment. Continuous education and appropriate interventions are needed to reduce the complications of these hazards.

Keywords: Dentistry, Musculoskeletal disorders, Occupational hazards, Oral healthcare professionals.

How to cite this article: Minal MK, Vathar J, Bafna $H$, Sonawane KR, Naik S, Powar S. Occupational Hazards in Oral Healthcare Professionals. J Oral Health Comm Dent 2018;12(2):62-66.

\section{Source of support: Nil}

Conflict of interest: None

\footnotetext{
${ }^{1,3,5}$ Assistant Professor, ${ }^{2}$ Associate Professor and Head, ${ }^{4}$ Dental Surgeon, ${ }^{6}$ Associate Professor

1-3,5Department of Public Health Dentistry, Government Dental College, Mumbai, Maharashtra, India

${ }^{4}$ Department of Public Health Dentistry, Sinhgad Dental College \& Hospital, Pune, Maharashtra, India

${ }^{6}$ Department of Orthodontics, Government Dental College Mumbai, Maharashtra, India

Corresponding Author: M Kshirsagar Minal, Assistant Professor, Department of Public Health Dentistry, Government Dental College, Mumbai, Maharashtra, India, Phone: +917066584979, e-mail: minalk115@gmail.com
}

\section{INTRODUCTION}

Working is the major source of our income, lifestyle, social life, and health too. Our surrounding environment may cause many health hazards to us. During the last two to three decades, epidemiologists have established an association between the risk factors and their effects on our health; one of these factors has been documented as occupation. ${ }^{1}$ Bernadino Ramazzini is considered as the father of occupational medicine and has established the role of occupation in health and diseases..$^{2-5}$ Occupational hazard has been defined as the risks arising out of employment to the health of a person. It can also refer to work, material, substance, process, or situation that causes accidents or disorders at the workplace. ${ }^{6}$ Workrelated disorders can be multifactorial in origin too. In such cases, work-related conditions can be one of the dominant factors contributing for the appearance and development of the health-related disorder. ${ }^{7}$

Previous literature suggests evidences that oral healthcare professionals are prone to a number of occupation-related disorders and most common health issues are percutaneous exposure incidents, dental materials, radiation, noise, musculoskeletal disorders (MSD), psychological problems, dermatitis, respiratory disorders, eye insults, etc. ${ }^{6-8}$ These disorders are also significantly influenced by factors like age, gender, working environment, and geographical factors. ${ }^{7}$ Daily, dentists and their staff are in contact with traumatized tissues, saliva, blood directly or indirectly; they may spread more infections through such practice. ${ }^{9,10}$

Occupational hazards can be classified as biological, biomechanical, chemical, physical, and psychological. These disorders also have an economic and security impacts when they reach a maximum level of severity. This may also affect working ability of a person leading to absences, unemployment, even early retirement or other work-related disorders.

\section{OBJECTIVES}

To summarize the important side of occupational hazards in oral healthcare professionals through thorough literature search.

\section{MATERIALS AND METHODS}

A thorough literature search was performed to understand and identify the updates related to Occupational hazards. 


\section{Inclusion Criteria}

Original research articles, comparative studies, systematic and narrative reviews especially emphasizing on occupational hazards.

Articles reported only in English were considered for the present review.

\section{Exclusion Criteria}

Articles in which only abstracts were available.

\section{Source of Literature}

Contact with subject experts, electronic database like PubMed, Google, and manual search were done till 2018 for the relevant literature using key phrase "Occupational hazards."

\section{Information Obtained}

Literatures, reports, questionnaire, and guidelines.

\section{Global Prevalence of Occupational Health Hazards}

A previous literature suggests that some Italian dental surgeries had shown high biocontamination. It was $33.3 \%$ for Legionella spp., ${ }^{9}$ Another study carried out in southern Thailand among dentists concluded that some of the most common occupational health problems were musculoskeletal pain (78\%) and percutaneous injury $(50 \%){ }^{11}$ A study on Lithuanian dentists revealed that fatigue $(94.7 \%)$ and back pain $(91.0 \%)$ are the most prevalent physical complaints. Hypertension, joint diseases, and allergy were the most prevalent diagnosed and treated diseases. ${ }^{12}$ A survey in Belgium revealed that Flemish dentists had reported low back pain, $54 \%$ (stresscorrelated); vision problems, $52.3 \%$ (age-correlated); infections, $9 \%$; allergies, $22.5 \%$ (mainly latex). ${ }^{13}$ A survey on occupational hazards among the clinical dental staff at the dental hospitals in Nigeria revealed that backache was found one of the most frequently experienced hazards in $47 \%$ of the subjects. ${ }^{14}$ Another study concluded that 33\% dentists in Southern Iran reported that they were suffering from lower back pain, while $28 \%$ had neck pain. ${ }^{15}$ In a study carried out in Riyadh, Saudi Arabia, among oral healthcare professionals to know the prevalence of hearing problems in the last 5 years, $16.6 \%$ of subjects reported to be suffering from tinnitus, 30\% of the subjects had difficulty in speech discrimination, and $30.8 \%$ of the subjects had speech discrimination in a background noise. ${ }^{16}$ In Australia, a study conducted showed that most of dentists $(87.2 \%)$ reported at least one symptom of MSD in the past few months. ${ }^{17}$

\section{Prevalence of Occupational Health Hazards in India}

In India, a study conducted on Navy dentists concluded that $47 \%$ of dentists faced an injury due to a sharp instrument during the past few months and backache was also the commonest hazard reported by $70.6 \%$ of the personnel followed by occasional anxiety and wrist ache. ${ }^{18}$ Another study concluded that $77 \%$ oral healthcare professionals from Chandigarh, India, reported that injury from sharp instruments was the most common occupational hazard. Other occupational problems are job-related stress $(43.3 \%)$, MSD (39.8\%), allergies (23.8\%) which were most common. ${ }^{19}$ Another study, which was conducted in Andhra Pradesh state concluded that $78 \%$ of dentists had at least one MSD symptom over the past few months and common areas which were affected most were neck (52\%), low back $(41 \%)$, shoulders $(29 \%)$, and wrist $(26 \%)$. It was seen that one-third of the practitioners $(40 \%)$ required sick leave from their practice. ${ }^{20}$

\section{Potential Sources for Occupational Hazards to Oral Healthcare Professionals ${ }^{2,3}$}

- Working for longer duration in physically improper positions.

- Percutaneous exposure incidents during close contact with patient's saliva and blood, facilitating the transmission of blood-borne pathogens.

- Exposure to infectious diseases including bioaerosols, radiation, etc.

- Exposure to various types of chemicals which are hazardous including mercury, silica, latex, etc., which act by local action, inhalation, or ingestion.

In most of the developing countries, it was seen that there is difficulty in obtaining accurate data regarding occupational health diseases. Several factors responsible may involve the following ${ }^{21}$ :

- Many problems go unnoticed and are therefore, not included or get ignored during data collection.

- Many problems even if oral healthcare professionals notice, they do not think that it is work-related.

- If health professionals or employers recognized some problems also that it is work-related, they do not report sometimes.

\section{Occupational Hazards}

\section{Psychological Hazards}

Not only physical impairments affect oral healthcare professionals' health. Job-related psychological disorders also contribute greatly. Factors that affect psychological status can be job-related stress, tension, depression, emotional 
exhaustion, and depersonalization. Stress is the most common psychological condition that occurs in the oral healthcare professionals. Previous literature suggests that oral healthcare professionals perceive their profession as more stressful compared with other occupations. ${ }^{22-25}$

\section{Physical Hazards}

The physical workload seems to put oral healthcare professionals at risk for the development of MSD. This may include chemical dependency and MSD which is directly related to practice, such as posture-related practices which may increase the risk of twisting and contorting the body, varicose veins, etc. ${ }^{24,26}$ Previous literature suggests that musculoskeletal problems are high among oral healthcare professionals compared with other professionals. ${ }^{27-29}$

\section{EFFECTS OF NOISE ${ }^{30}$}

\section{Auditory Effects}

- Auditory fatigue $(90 \mathrm{~dB}$ or $4000 \mathrm{~Hz})$

- Temporary deafness $(4000-6000 \mathrm{~Hz})$

- Permanent deafness $(100 \mathrm{~dB})$

\section{Nonauditory Effects}

- Interference with speech

- Annoyance

- Reduction in efficiency

- Physiologic damage

\section{Musculoskeletal Disorder}

Musculoskeletal disorder is one of the common health problems and 38 to $82 \%$ prevalence has been reported. Musculoskeletal problems are basically a group of conditions which involve nerves, tendons, muscles, and their supporting structures, such as intervertebral disks. It was seen that young and less experienced professionals face more MSD compared with older and experienced ones. Common musculoskeletal problems include, low back pain, shoulder pain, headache, hand and wrist pain. Low back pain is more prevalent than other types. Musculoskeletal problems are mostly due to unidirectional twisting of the trunks repeatedly, working in one position for long, prolonged static periods, and operator's flexibility. ${ }^{30}$

\section{Infectious Hazards}

Transmissible diseases like human immunodeficiency virus, hepatitis B virus (HBV), hepatitis C virus, Mycobacterium tuberculosis are currently of greatest concern to healthcare professional. Oral healthcare professional may get infected by a cut, wound or injury, needle stick injury, aerosols of saliva, gingival fluid, natural organic dust particles, traces of materials, etc. Epidermis of hands, oral epithelium, nasal epithelium, epithelium of upper airways, bronchial tubes, alveoli, and conjunctival epithelium are some of the main entry points for infections to a person. In order to overcome the infection spread, a thorough knowledge about the infection, mode of transmission, and safety measures are required. ${ }^{30}$

\section{Allergic Reactions}

It was seen that most of the allergic skin reactions are caused by latex gloves, but dental materials, solvents, lubricating oils, detergents, $\mathrm{X}$-ray processing chemicals, etc., may also be responsible for the same. ${ }^{31}$

\section{lonizing Radiation}

There is always an exposure to ionizing radiation due to the use of X-ray machines in the dental office. ${ }^{32,33}$ Use of safety glasses, appropriate shields can minimize or eliminate the possibility of exposure to radiations.

\section{Anesthetic Gases in the Dental Office}

Oral healthcare professionals who use nitrous oxide gas on a regular basis over an extended period of time face problems. $^{33,34}$

\section{Legal Hazards}

In every country, there are relevant statutes and regulations which apply to the practice of oral healthcare profession. The contravention of any of these may warrant that legal actions be brought against an oral healthcare professional particularly in developed countries where the citizens appear more aware of their rights. Knowledge regarding hazard awareness and prevention of legal risks is important for safe working environment and it should be made known to all clinical workers of all the hospitals. ${ }^{5}$

\section{Prevention of Occupational Hazards $\mathbf{s}^{31,33,35,36}$}

- Infection control and proper handling of potentially infected materials are very important regarding transmission of infection.

- Immunization: It can be one of the useful measures. All oral healthcare professionals should be advised to get immunized to avoid infectious diseases like HBV.

- For the reduction of aerosols and vapor dangers, barrier techniques like gloves, masks, protective eye wear, high power suction, good ventilation are very helpful. Hypoallergic non-latex gloves are proposed to overcome latex allergy.

- Lead aprons, periodic maintenance of the X-ray machine and radiation level sensors are useful for prevention of radiation hazards. 
- In case of MSD, knowledge in ergonomics may be of great importance.

- Some previous literature suggests yoga as an alternative remedy to overcome occupational hazards, but more information is not available on the same. ${ }^{37}$

\section{CONCLUSION}

Globally, oral healthcare professionals have reported poor general health and suffering from various workrelated health problems. The oral healthcare profession has always been known as uneasy occupation; therefore, one must take into account serious work-related difficulties. Students should also be aware of the health risks in oral healthcare profession. Secondly, all sorts of protection must be used during treatment in order to prevent infectious diseases and other injuries. Furthermore, oral healthcare professionals must be taught about coping with stress patterns. They must be aware of the importance of maintaining good physical and mental health.

\section{REFERENCES}

1. Al-Sayagh GD. The occupational hazards and diseases among dentists in Mosul City: musculoskeletal pain, eye problem and hepatitis. Al-Rafidain Dent J 2006;6(2):136-143.

2. Singh RK, Kamath AT, Bhagania MK, Bansal T. Occupational hazards awareness and preventive practices among students of a dental institution in South India. Int J Med Sci Public Health 2016 Nov;5(11):2312-2315.

3. Joshi M, Tailor M, Nair A. Awareness of basic protocols followed in routine dentistry: a hospital based survey in Dental Institution of Central Gujarat. NJIRM 2015;6(3):74-79.

4. Asuzu, MC. Occupational health: a summary, introduction, and outline of principle. Ibadan: Afrika-Links Books; 1994. pp. 1-11.

5. Fasunloro A, Owotade FJ. Occupational hazards among clinical dental staff. J Contemp Dent Pract 2004 May;5(2):134-152.

6. Agrawal N, Gupta ND, Bey A, Garg AK, Sharma VK. Occupational hazards in modern dentistry: a review. Adv J 2014 Dec;1(1):1-9.

7. Vodanović M, Galić I, Kelmendi J, Chalas R. Occupational health hazards in contemporary dentistry-a review. Rad 530. Med Sci 2017 Mar;44:25-41

8. Baghla P, Desai V, Sharma R, Mathur E, Sareen M, Dhaka P, Phore S, Sobti P. Awareness of occupational hazards among dentists: a questionnaire based study. Int J Appl Dent Sci 2015 Aug;1(4):27-30.

9. Castiglia P, Liguori G, Montagna MT, Napoli C, Pasquarella C, Bergomi M, Fabiani L, Monarca S, Petti S; SItI Working Group Hygiene in Dentistry. Italian multicenter study on infection hazards during dental practice: control of environmental microbial contamination in public dental surgeries. BMC Publ Health 2008 May;8:187.

10. Hovius M. Disinfection and sterilisation: the duties and responsibilities of dentists and dental hygienists. Int Dent J 1992 Aug;42(4):241-244.

11. Chowanadisai S, Kukiattrakoon B, Yapong B, Kedjarune U, Leggat PA. Occupational health problems of dentists in southern Thailand. Int Dent J 2000 Feb;50(1):36-40.
12. Puriene A, Aleksejuniene J, Petrauskiene J, Balciuniene I, Janulyte V. Self-reported occupational health issues among Lithuanian dentists. Ind Health 2008 Aug;46(4):369-374.

13. Cleveland JL, Barker LK, Cuny EJ, Panlilio AL; National Surveillance System for Healthcare Workers Group. Preventing percutaneous injuries among dental healthcare personnel. J Am Dent Assoc 2007 Feb;138(2):169-178.

14. Di Giuseppe G, Nobile CG, Marinelli P, Angelillo IF. A survey of knowledge, attitudes, and behavior of Italian dentists toward immunization. Vaccine 2007 Feb;25(9): 1669-1675.

15. Pargali N, Jowkar N. Prevalence of musculoskeletal pain among dentists in Shiraz, Southern Iran. Int J Occup Environ Med 2010 Apr;1(2):69-74.

16. AlWazzanKA,AlQahtaniMQ,AlShethriSE,AlMuhaimeedHS, Khan N. Hearing problems among dental personnel. J Pak Dent Assoc 2005;14:210-214.

17. Leggat PA, Smith DR. Musculoskeletal disorders self-reported by dentists in Queensland, Australia. Aust Dent J 2006 Dec;51(4):324-327.

18. Chopra SS, Pandey SS. Occupational hazards among dental surgeons. Med J Armed Forces India 2007 Jan;63(1):23-25.

19. Mehta A, Gupta M, Upadhyaya N. Status of occupational hazards and their prevention among dental professionals in Chandigarh, India: a comprehensive questionnaire survey. Dent Res J (Isfahan) 2013 Jul;10(4):446-451.

20. Muralidharan D, Fareed N, Shanthi M. Musculoskeletal disorders among dental practitioners: does it affect practice? Epidemiol Res Int 2013;2013:716897.

21. Al-Khatib IA, Ishtayeh M, Barghouty H, Akkawi B. Dentists' perceptions of occupational hazards and preventive measures in East Jerusalem. East Mediterr Health J 2006 Jan-Mar;12(12):153-160.

22. Puriene A, Janulyte V, Musteikyte M, Bendinskaite R. General health of dentists. Literature review. Stomatologija 2007;9(1):10-20.

23. Alexander RE. Stress-related suicide by dentists and other healthcare workers. Fact or folklore. J Am Dent Assoc 2001 Jun;132(6):786-794.

24. Winwood PC, Winefield AH, Lushington K. The role of occupational stress in the maladaptive use of alcohol by dentists: a study of South Australian general dental practitioners. Aust Dent J 2003 Jun;48(2):102-109.

25. Newton JT, Mistry K, Patel A, Patel P, Perkins M, Saeed K, Smith C. Stress in dental specialists: a comparison of six clinical dental specialties. Prim Dent Care 2002 Jul;9(3): 100-104.

26. Al Wazzan KA, Almas K, Al Shethri SE, Al-Qahtani MQ. Back \& neck problems among dentists and dental auxiliaries. J Contemp Dent Pract 2001 Aug;2(3):17-30.

27. Alexopoulos EC, Stathi IC, Charizani F. Prevalence of musculoskeletal disorders in dentists. BMC Musculoscelet Disord 2004 Jun;5:16.

28. Fish DR, Morris-Allen DM. Musculoskeletal disorders in dentists. NY State Dent J 1998 Apr;64(4):44-48.

29. Rising DW, Bennet BC, Hursh K, Plesh O. Reports of body pain in a dental student population. J Am Dent Assoc 2005 Jan;136(1):81-86.

30. Raja K, Tilak AH. Occupational hazards in dentistry and its control measures-a review. World J Pharm Pharm Sci 2014 Dec;3(6):397-415. 
31. Rubel DM, Watchorn RB. Allergic contact dermatitis in dentistry. Australas J Dermatol 2000 May;41(2):63-69.

32. Szymanska J. Occupational hazards of dentistry. Ann Agric Environ Med 1999 Feb;6(1):13-19.

33. Shuhaiber S, Einarson A, Radde IC, Sarkar M, Koren G. A prospective controlled study of pregnant veterinary staff exposed to inhaled anesthetics and X-rays. Int J Occup Med Environ Health 2002;15(4):363-373.

34. Henderson KA, Matthews IP. Environmental monitoring of nitrous oxide during dental anaesthesia. Br Dent J 2000 Jun;188(11):617-619.
35. EIP Associates. Mercury amalgam treatment technologies for dental offices. Palo Alto (CA): EIP Associates; 2000. [cited 2002 Jan 4]. Available from: http:/ / www.bandwidthmarket.com/ resources/mirror/government/state/www.city.palo-alto. ca.us/cleanbay/pdf/denttech.pdf.

36. Kumar RS, Manish GN, FerreiraAM. Occupational hazards among dental surgeons. Indian J Occup Environ Med 2000;4(3):139-141.

37. Sumathi G, Sangeetha K, Tharani Kumar S. Prevalence of yoga as an alternative therapy for the treatment of occupational hazards among dentists in Chennai, India- a comprehensive study. IJIRCCE 2014 Feb;2(2):3189-3196. 